\title{
Effects of Light on Saccharide Wastewater Treatment and Resource Recovery by Proteiniphilum acetatigenes PSB-W
}

\author{
Qingping $\mathrm{Hu}^{1,2 *}$, Xiaoli Gao ${ }^{2}$ \\ ${ }^{1}$ Modern College of Humanities and Sciences of Shanxi Normal University, Linfen, China \\ ${ }^{2}$ College of Life Science, Shanxi Normal University, Linfen, China \\ Email: ^hqp72@163.com
}

How to cite this paper: Hu, Q.P. and Gao, X.L. (2020) Effects of Light on Saccharide Wastewater Treatment and Resource Recovery by Proteiniphilum acetatigenes PSB-W. Open Access Library Journal, 7: e6348. https://doi.org/10.4236/oalib.1106348

Received: April 23, 2020

Accepted: May 26, 2020

Published: May 29, 2020

Copyright $\odot 2020$ by author(s) and Open Access Library Inc.

This work is licensed under the Creative Commons Attribution International License (CC BY 4.0).

http://creativecommons.org/licenses/by/4.0/ (c) (i) Open Access

\begin{abstract}
Photosynthetic bacteria (PSB) wastewater treatment is a new method with great resource recovery potential. In order to improve the biomass and valuable resources of bacteria in the wastewater treatment of photosynthetic bacteria, the effects of different light conditions on the efficiency of Proteiniphilum acetatigenes $\mathrm{PSB}-\mathrm{W}$ in the treatment of sugar wastewater and the production of bacteria and carotenoids in the wastewater were analyzed from three aspects of light source, light intensity and light period. Under the principle of priority of pollutant removal efficiency, the red LED light was selected with the light intensity of 4000 Lux, 16L (light):8D (dark) for light cycle, and the best efficiency of wastewater removal and bacterial yield were obtained when the culture time was $3 \mathrm{~d}$, Chemical oxygen demand (COD) removal rate was $80.9 \%$, bacterial $\mathrm{OD}_{600}$ was $0.907 \pm 0.023$, carotenoid yield was $7.83 \pm 0.27$ $\mathrm{mg} / \mathrm{L}$, respectively. These results show that PSB-W strains can provide more biomass and valuable substances in suitable environment. It provides a theoretical basis for the realization of wastewater recycling.
\end{abstract}

\section{Subject Areas}

Biochemistry, Bioengineering

\section{Keywords}

Wastewater Treatment, Bacteria Resource, Carotenoids, Wastewater Recycling

\section{Introduction}

About three-quarters of the earth's area are covered by water, which is very rich, 
but the freshwater resources that can be used by humans are only seven parts per 100,000 . In today's world, with the rapid development of economy, people's living standards are increasing, and the scale of cities is expanding, which is followed by the demand for water resources, as well as the increasing discharge of domestic and industrial wastewater, leading to increased pollution of water resources, the world is facing uneven distribution of water resources and severe shortages [1]. Although the current wastewater treatment work has achieved phased results, there are still many deficiencies in wastewater treatment technology, for example, the traditional physical and chemical methods have high costs, high energy consumption, and will cause a large amount of secondary pollution such as excess sludge and chemical reagents [2]. The International Water Association (IWA) proposed at the 2018 Global Water and Wastewater Frontier Technology Conference that the theme of wastewater treatment in recent years is to achieve resource recovery. Therefore, the wastewater treatment technology of PSB has become the first-choice strain for realizing waste water resources with its advantages of high efficiency, environmental protection and abundant high-value bacterial cells, which has attracted wide attention from researchers [3].

Photosynthetica variety of bacteria is a type of prokaryotic microorganisms with a primitive light energy synthesis system. They are widely distributed in nature and are very common in waters with high concentrations of putrefactive organic substances, and have many functions such as nitrogen fixation, dehydrogenation, carbon fixation, sulfide oxidation, so it has a good treatment effect on many kinds of wastewater [4]. As early as the 1960s, Japanese scientist M. Kobayashi studied the purification rule of organic sewage in nature and found that PSB played a major role in the process of natural sewage self purification. Since then, PSB wastewater treatment has developed significantly. Scientists have found that PSB could be used to treat various types of wastewater, including soybean wastewater, domestic wastewater, dye wastewater, shrimp farm wastewater, poultry slaughterhouse wastewater, citric acid wastewater [5] [6]. Biomass can accumulate when applying PSB to treat wastewater, this biomass is a good source of valuable substances, including carotenoids and bacteriochlorophyll, Polyhydroxyalkanoate, coenzyme Q10, 5-aminolevulinic acid protein, antimicrobial agents, and pantothenic acid [7]. Among these high-value products from PSB, carotenoids are more attractive. The remarkable physiological functions of carotenoids are as antioxidants to quench singlet oxygen and capture oxygen free radicals, and as nutritional supplements, food pigments and feed colorants in industry, which can be used in nutritional supplements, medicines, and animal feed, and result in great economic benefits [8] Therefore, it is attractive to apply PSB to wastewater treatment together with biomass recycling and carotenoid production. PSB will be able to realize the recycling of bacterial resources while treating wastewater, and provide new ideas for wastewater treatment [9].

PSB can grow with light as energy, absorb and capture light energy by photosynthetic pigment system to form energy, and promote the trans-membrane transport of materials [10]. Light conditions are the most important parameter 
for PSB growth and wastewater treatment because they can directly affect the metabolic pathways of PSB. Sugar wastewater is a type of nutrient wastewater with abundant substances such as carbon, nitrogen, phosphorus, etc. In other words, it can be used as a growth medium for microorganisms, accumulate bacteria and synthesize valuable substances while treating sewage. Therefore, in this study, the $P$. acetatigenes $\mathrm{PSB}-\mathrm{W}$ was used as the experimental strain, which was a high-yield carotenoid PSB isolated in the early stage of the laboratory [6]. The effects of light conditions on the treatment efficiency of PSB-W strain on simulated saccharide wastewater and the growth amount of bacteria and carotenoid yield in wastewater were investigated by controlling the three factors of different light sources, light intensity and photoperiod. It provides a theoretical basis for the recycling of PSB wastewater treatment [7].

\section{Materials and Methods}

\subsection{Materials}

A PSB-W strain was isolated from water purification agent and stored in the microbiology laboratory of Shanxi Normal University. Under the light of $60 \mathrm{~W}$ tungsten filament lamp (1500 Lux), $30^{\circ} \mathrm{C}$ constant temperature anaerobic culture was conducted for 3 days. Ensure that bacteria in logarithmic growth period are inoculated when used for experimentation.

The non-toxic simulated sugar wastewater can provide nutrition for the growth of PSB, including sucrose $(5 \mathrm{~g} / \mathrm{L})$, sodium bicarbonate $(1 \mathrm{~g} / \mathrm{L})$, malic acid $(3 \mathrm{~g} / \mathrm{L})$, potassium dihydrogen phosphate $(0.4 \mathrm{~g} / \mathrm{L})$, ammonium sulfate $(2 \mathrm{~g} / \mathrm{L})$, magnesium sulfate heptahydrate $(0.2 \mathrm{~g} / \mathrm{L})$ wastewater with initial COD of 6000 $\mathrm{mg} / \mathrm{L}$ and $\mathrm{pH}$ value of 7.0. The wastewater should be stored at $4^{\circ} \mathrm{C}$ before used Yang [1].

\subsection{Experimental Methods}

Light Source: The PSB-W bacteria were added into the simulated wastewater according to the proportion of volume ratio (bacteria: wastewater $=1: 4$ ) and cultured with 6 different light sources, namely red LED, yellow LED, green LED, blue LED, white LED and incandescent lamp.

Light Intensity: The PSB-W bacteria were added into the simulated sewage according to the proportion of volume ratio (bacteria: waste $=1: 4$ ), the best light source was selected, and the Lux of 1000, 2000, 4000, 6000 and 8000 was set.

Light cycle: The fermentation broth of strain PSB-W was added into the simulated sewage according to the proportion of volume ratio (bacteria:waste = 1:4), the optimal Light source and Light intensity were selected, and four different Light/Dark cycles were set. The Light duration (L):Dark duration (D) respectively was set to $8 \mathrm{~L}: 16 \mathrm{D}, 12 \mathrm{~L}: 12 \mathrm{~d}, 16 \mathrm{~L}: 8 \mathrm{D}, 24 \mathrm{~L}: 0 \mathrm{~d}$ in four groups.

\subsection{Analysis Methods}

Different samples were collected and the removal rate of COD was determined 
by potassium dichromate method. The biomass absorbance was measured at 600 nm using a spectrophotometer (722 Jinghua, China). The carotenoids were extracted from PSB with the volume ratio of organic solvent (acetone: methanol = 7:2) and measured at $473 \mathrm{~nm}$ using a spectrophotometer. The carotenoids content was calculated from Equation (1).

$$
\text { Caroteniod yield }=A_{473} \times 10,000 /(250 \times L \times W)
$$

where A473 were the absorbencies of the extracts at $473 \mathrm{~nm} ; L$ was the path-length of the cuvette used in the spectrophotometer; and $\mathrm{W}$ was the initial amount $(\mathrm{g})$ of samples divided by the final volume $(\mathrm{mL})$ of extracts obtained [1].

\subsection{Statistical Methods}

Each experiment was repeated three times and three parallel measurements were made to ensure the accuracy of the data. Tukey was used to test the significance level of the analysis data, and the P value was lower than 0.05 .

\section{Results and Discussion}

\subsection{Effect of Light Source on Treatment of Saccharide Wastewater by PSB-W Bacteria}

\subsubsection{Effects of Light Source on COD Removal in PSB Wastewater Treatment}

COD reflects the degree of water pollution by reducing substances, including organic matter, nitrite, iron salt, sulfide, COD can be used as a comprehensive indicator of the relative content of organic matter. The COD removal rate of wastewater treated by strain PSB-W under different light sources was tested. The results are shown in Figure 1, which shows that different light sources have different effects on COD removal rate and reach the peak value at different times. When the light source is red LED, the strain has the best treatment effect on the simulated wastewater, and the COD removal rate reaches $77.1 \%$ on the 4 th day; when the light source is incandescent lamp, the wastewater treatment effect takes the second place, and the COD removal rate reaches $74.6 \%$. The COD removal rate of red LED, blue LED, green LED and incandescent lamp all decreased in the later period, because bacteria will decompose in the wastewater, and as time goes on, it may cause the deterioration of the wastewater environment and inhibit the growth of bacteria.

\subsubsection{Effects of Light Source on Biomass in PSB Wastewater Treatment} For PSB wastewater treatment technology, biomass is one of the most important parameters to consider, since biomass determines the capacity of resource recovery. The biomass concentrations under the six different light sources followed the same trend (Figure 1 ) and $p<0.05$ according to ANOVA, indicated that light sources had significant influence on PSB biomass. As shown in Figure 2. Under the irradiation of red LED, blue LED and incandescent lamp, PSB-W bacteria all grow well, and the optical density increases with time. This indicated that PSB-W strains could use sugar wastewater as raw material for growth and 


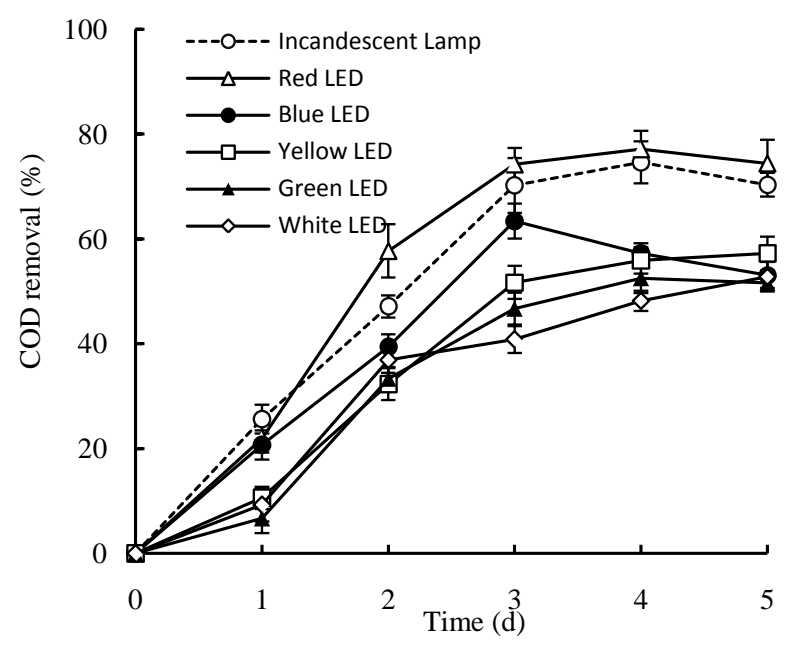

Figure 1. Effect of different light sources on COD removal rate.



Figure 2. Effect of different light sources on biomass of PSB-Win wastewater.

reproduction, in which, under the irradiation of red LED lamp, the biomass reached the highest, and the light density reached $1.024 \pm 0.032$ on the third day of culture. Under the incandescent lamp, the growth was relatively stable, but the difference in the final light density was not large. The growth rate of the yellow LED, white LED and green LED groups was significantly lower than that of the other three groups, and the growth condition was poor. In this experiment, the power of the red LED is $18 \mathrm{w}$, and the power of the incandescent lamp is 40 $\mathrm{w}$. When the irradiation time is the same, the red LED is more energy-saving than the incandescent lamp. Considering the growth amount and energy consumption of strain, red LED is the best light source.

\subsubsection{Effects of Light Source on Carotenoid in PSB Wastewater Treatment}

Carotenoids have a very important application value. The effect of different light sources on the production of carotenoids in PSB-W waste water was studied. The results are shown in Figure 3. As a whole, the order of the effect of light 


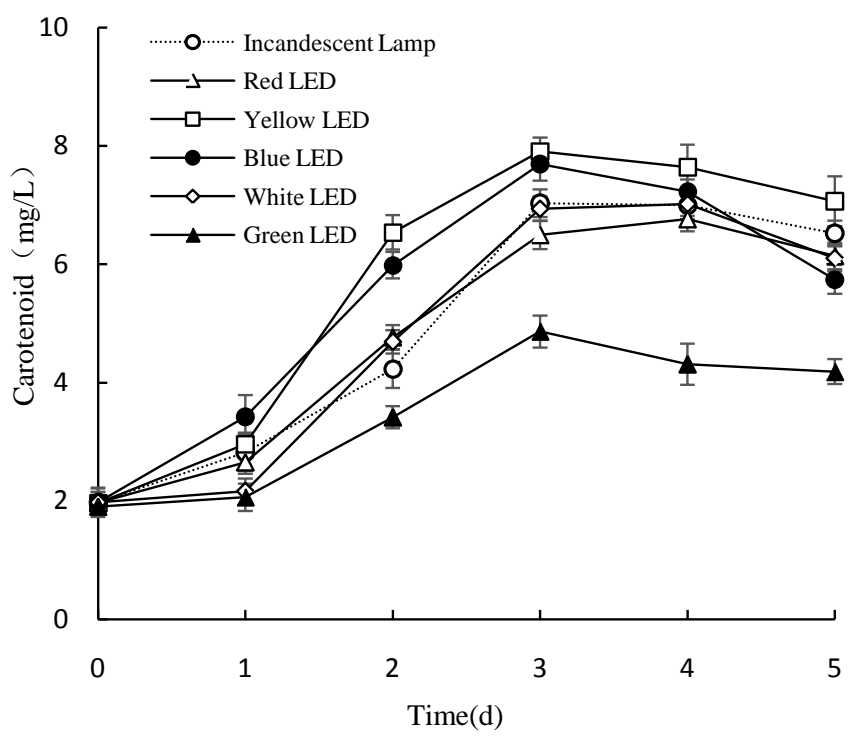

Figure 3. Effect of different light sources on the yield of carotenoids in wastewater.

sources on the content of carotenoids from the highest to the lowest is: yellow LED > blue LED > incandescent lamp > white LED > red LED > green LED. Under the yellow LED light, the carotenoid content is the highest, reaching 7.91 $\pm 0.11 \mathrm{mg} / \mathrm{L}$. under the red light and green light, the pigment content is low, which is not suitable for the accumulation of pigment in the wastewater treatment by PSB-W.

\subsection{Effect of Light Intensity on Treatment of Saccharide Wastewater by PSB-W Bacteria}

\subsubsection{Effects of Light Source on COD Removal in PSB Wastewater Treatment}

As shown in Figure 4, when the red LED light is selected as the light source, PSB-W has a better treatment effect on sugar simulated wastewater in the light intensity range of 2000 - $6000 \mathrm{Lux}$, and the COD removal rate increases with the extension of time. Under 4000 Lux light, the COD removal rate reaches the highest value, reaching 79.4\%. However, due to the photoinhibition of photosynthetic bacteria, COD removal rate decreased with the continuous increase of light intensity, and the treatment effect was the worst at 8000 Lux.

\subsubsection{Effects of Light Source on Biomass in PSB Wastewater Treatment}

The effect of different light intensity of red LED as light source on the growth of strain PSB-W in simulated sugar wastewater was studied [11]. The results are shown in Figure 5. Too low or too high light intensity will inhibit the growth of strain PSB-W, and the light intensity will increase from 1000 Lux to 6000 Lux, the biomass of PSB-W increased with the increase of light intensity, which was because more light energy provided more energy for photosynthetic cells. However, the growth of PSB-W decreased sharply under the light intensity of 8000 Lux, indicating that there was a certain light threshold when PSB stopped growing due to photoinhibition. Under the light intensity of 1000 Lux and 8000 Lux, 


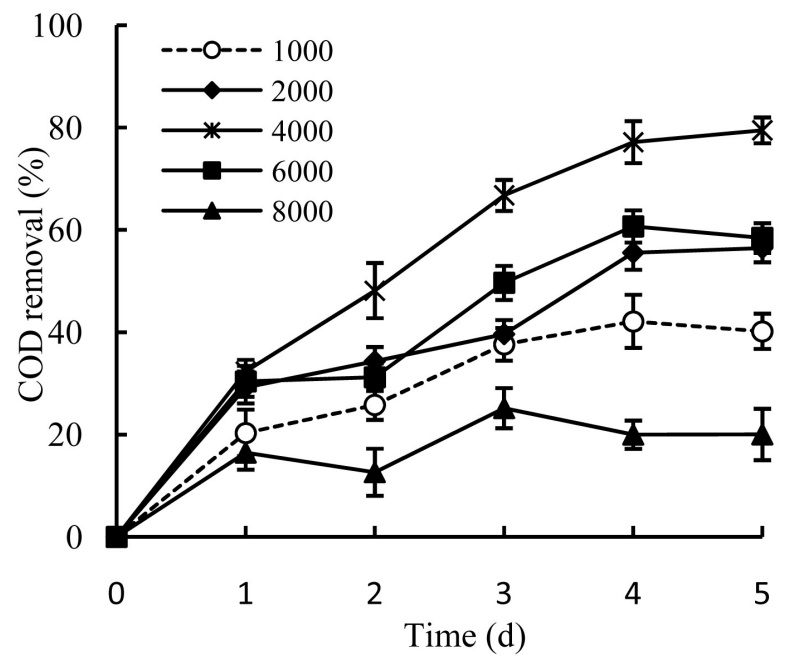

Figure 4. Effect of different light intensity on COD removal rate.

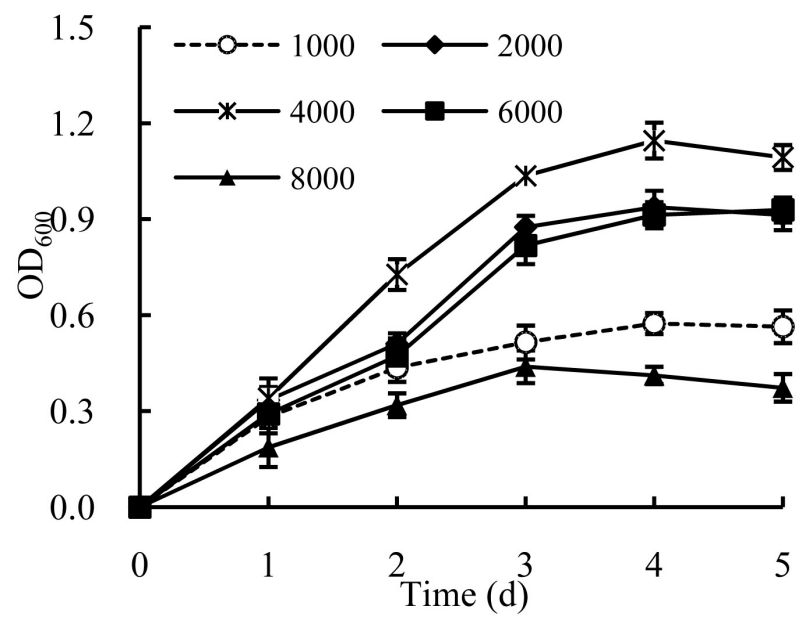

Figure 5. Effect of different light intensity on biomass of in wastewater.

the biomass was significantly lower than that under the light intensity of 2000, 4000 and 6000 Lux; under the light intensity of 4000 Lux, the biomass reached the highest, and the optical density value was $1.146 \pm 0.052$. Under the light intensity of 8000 Lux, on the third day, the highest value of light density was only $0.439 \pm 0.021$, and the final biomass was also lower than that of $1000 \mathrm{Lux}$. Obviously, strong light was more unfavorable to the growth of PSB-W.

\subsubsection{Effects of Light Source on Carotenoid in PSB Wastewater Treatment}

Carotenoids determines the number of it can capture light energy, a direct impact on the growth of photosynthetic bacteria, under different light intensity on the carotenoid content of PSB-W was analyzed, and the influence of can be seen from the Figure 6, in all light conditions, the output of carotenoids are within $2 \mathrm{~d}$ before there is a growing trend, carotenoid production in $2000 \mathrm{Lux}$ minimum and maximum yield under 8000 Lux light intensity reached $8.03 \pm$ $0.07 \mathrm{mg} / \mathrm{L}, 2$ times that of 2000 Lux group. This may be because the phenomenon 


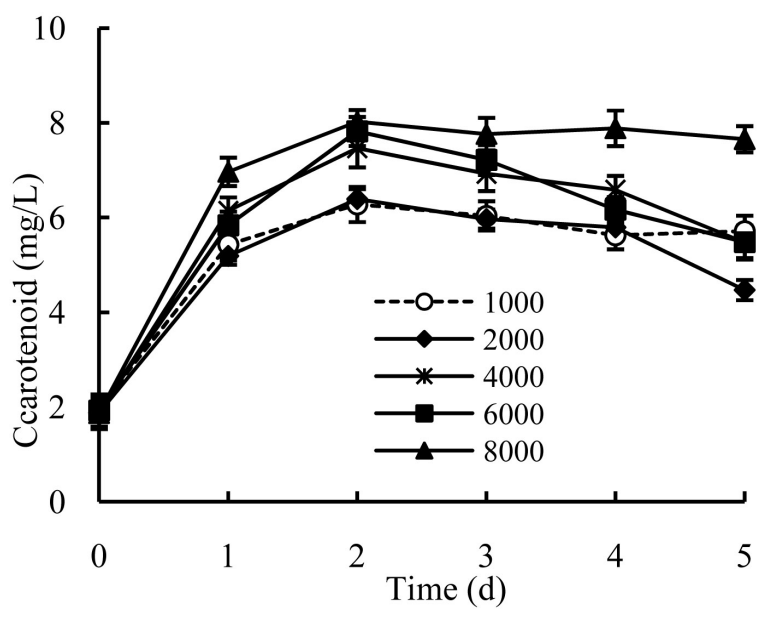

Figure 6. Effect of different light intensity on the yield of carotenoids in wastewater.

of light inhibition caused by excessive light intensity was not conducive to the growth of the strain and stimulated the production of carotenoids by PSB-W for photochemical protection, which resulted in the continuous increase of carotenoids yield under strong light intensity.

\subsection{Effect of Light Source on Treatment of Saccharide Wastewater by PSB-W Bacteria}

\subsubsection{Effects of Light Source on COD Removal in PSB Wastewater Treatment}

The light received by PSB growing in the nature changes with the change of sunlight, and the natural light is discontinuous. Therefore, different light (L)/dark (D) duration directly affects the energy metabolism pathway of bacteria. Under the condition that the red LED is the light source and the light intensity is 4000 Lux, the influence of different light periods on the sewage treatment efficiency of PSB-W is further investigated. The results are shown in Figure 7. With the extension of light cycle time in different light cycle, the effect on COD removal rate is different. It reaches the maximum when the photoperiod is $16 \mathrm{~L}: 8 \mathrm{D}$, and the COD removal rate reaches $80.9 \%$. However, on the whole, the effect of light dark cycle is better than continuous light.

\subsubsection{Effects of Light Source on Biomass in PSB Wastewater Treatment}

As shown in Figure 8, the biomass of PSB-W in wastewater reached the highest at $12 \mathrm{l}: 12 \mathrm{~d}$ of light dark cycle on the 3rd day, and the light density value reached $1.239 \pm 0.044$, showing a downward trend with the extension of time. At the 5th day, the final biomass of PSB-W in $16 \mathrm{~L}: 8 \mathrm{D}$ group was the maximum, the light density was $0.907 \pm 0.023$, and the light/dark cycle increased from $8 \mathrm{~h} / 16 \mathrm{~h}$ to 16 $\mathrm{h} / 8 \mathrm{~h}$. The biomass of the bacteria showed an increasing trend, indicating that more light duration provided more energy for the growth of PSB, which was basically consistent with the removal rate of COD, indicating that the appropriate photoperiod was more conducive to the growth of PSB and the treatment of wastewater. 


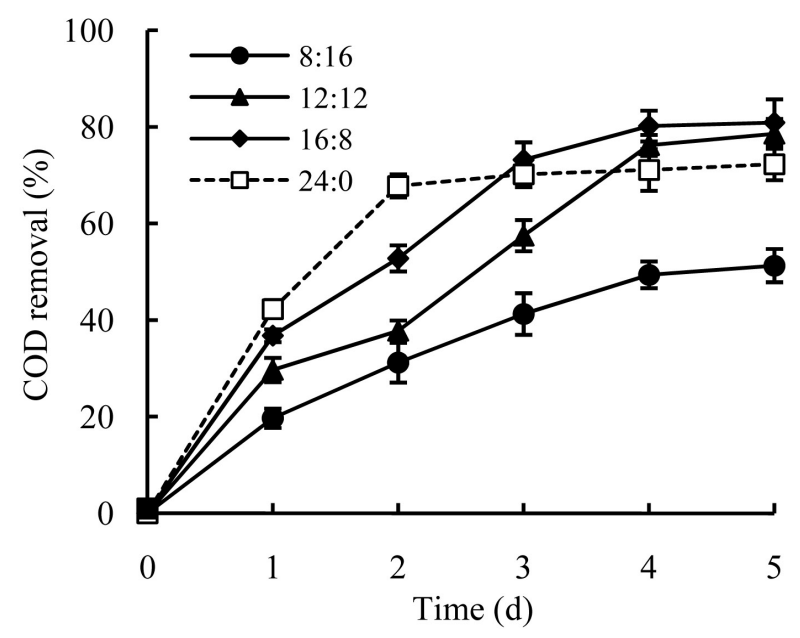

Figure 7. Effect of different photoperiods on COD removal rates.

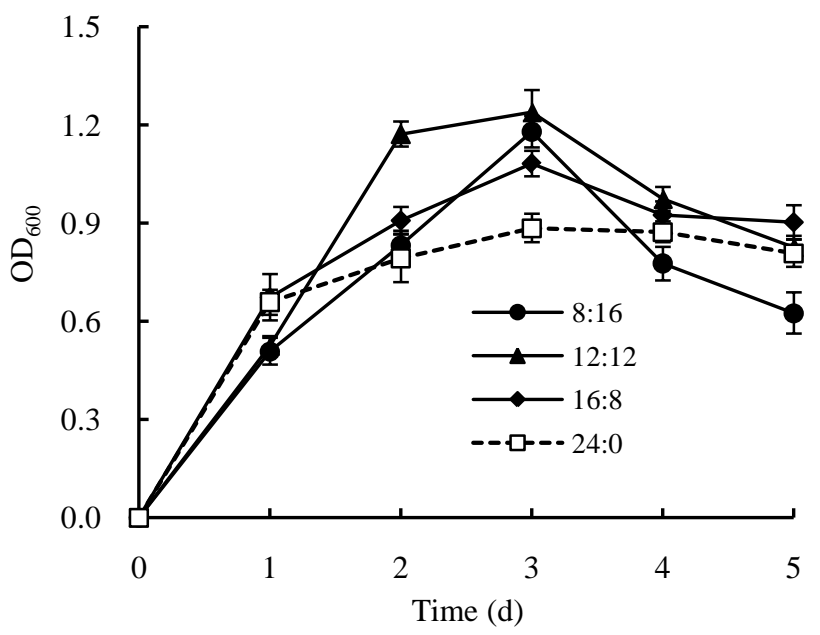

Figure 8. Effect of different photoperiods on biomass in wastewater.

\subsubsection{Effects of Light Source on Carotenoid in PSB Wastewater Treatment}

The effects of different light/dark periods on the carotenoid yield of PSB were studied. The result is shown in Figure 9. The highest yield was $8.96 \pm 0.52 \mathrm{mg} / \mathrm{L}$ at the photophase of $24 \mathrm{~L}: 0 \mathrm{D}$ at the $3 \mathrm{rd}$ day, and the highest yield was $7.83 \pm 0.27$ $\mathrm{mg} / \mathrm{L}$ at the 5 th day in the $16 \mathrm{~L}: 8 \mathrm{D}$ group. Carotenoids production increased with the increase of light duration in the first three days, indicating that the role of carotenoids in capturing and transmitting light energy played an important role in the growth of photosynthetic bacteria. At the later stage of wastewater treatment, the output of carotenoids decreased to different degrees, and it was speculated that the role of photophosphorylation pathway began to decrease in the later stage of wastewater treatment. Comprehensive consideration sewage treatment effect and bacterial yield, 16L:8D was selected as the optimal light cycle.

\section{Conclusion}

PSB wastewater treatment process is a new biological wastewater treatment 


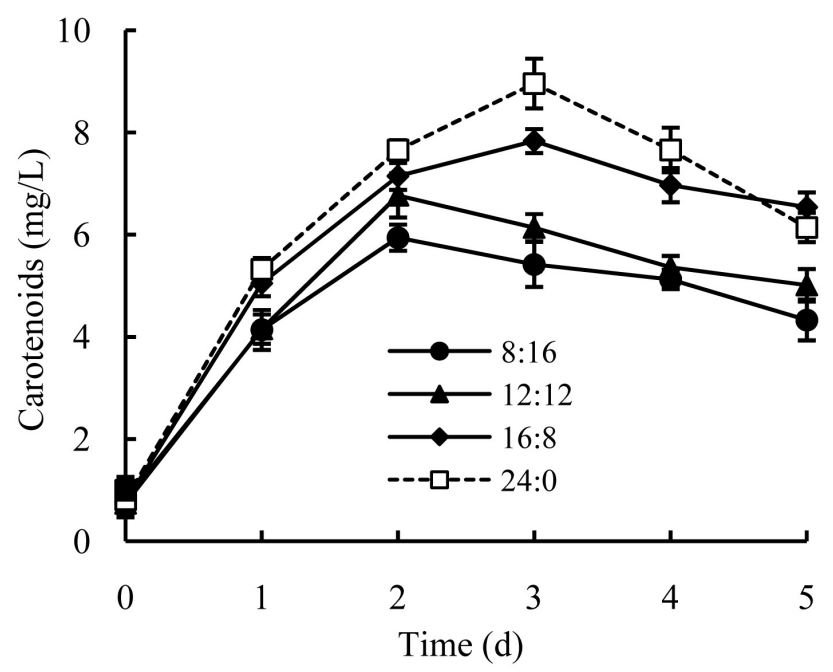

Figure 9. Effect of different photoperiods on the yield of carotenoids in wastewater.

technology with great potential compared with the traditional wastewater treatment process. There are many kinds of photosynthetic bacteria, which can produce many kinds of high-value substances [12]. Carotenoid is the most important one, which is a natural pigment with high application value. The research on the synthesis of biological carotenoid was previously conducted in the culture medium. In addition, the cost of the culture medium accounts for a considerable proportion in the production of PSB and the synthesis of carotenoids [10]. The method of replacing the culture medium with harmless wastewater can not only reduce the cost, but also realize the removal of pollutants and the synthesis of carotenoids by wastewater. PSB also has strong adaptability to the environment, and can flexibly change the metabolic pathway according to the growth environment [13]. According to the principle of bacterial photosynthetic process, in the early stage of culture, the energy and metabolic intermediates in cells are usually used for cell growth [14]. Light is an important factor affecting the physiological activity of photosynthetic bacteria, which proves that these are important for the physiological activity of PSB factors [6]; however, the impact on the treatment of PSB-W wastewater is unclear. Therefore, this paper explores the feasibility of high carotenoid strain PSB-W in the wastewater treatment from three aspects of light source, light intensity and light cycle. The results show that these three light factors have a certain impact on the treatment of PSB wastewater [15] [16]. In wastewater treatment under the principle of efficiency first, choose red LED lights, light intensity of 4000 Lux, light dark cycle for 16L:8D, when training time for the $3 \mathrm{~d}$ strain biomass and COD removal rate as the optimal light conditions, The wastewater treatment efficiency also obtains valuable products [17]. In Lee study, carotenoid yield decreased with the increase of light/dark cycle, but in this study, pigment yield and wastewater treatment effect under light/dark cycle irradiation were better than under continuous light [9]. Kuo's studied the effect of light source on the growth of PSB. Their research shows that blue LED is the best for PSB growth, and the possible explanation is 
that different strains of PSB have different characteristic absorption spectra [14]. Blue light can be emitted in the range of $400-495 \mathrm{~nm}$ and is absorbed by carotenoids, which are the main pigments in PSB [17]. The difference in the absorptive capacity of the pigment may determine the optimal light source, which may be caused by the culture time, the use of different strains and the medium [18]. We believe that the results of our research will help promote the development and application of PSB-W wastewater treatment technology and bring other environmental benefits, such as reducing surface and groundwater pollution, and transforming waste into treasure. Therefore, PSB-W bacteria have the potential to improve the wastewater treatment process without any additional costs, use biomass for energy production, and realize wastewater recycling.

\section{Acknowledgements}

This work was financially supported by the Natural Science Foundation Project of Shanxi Province (201801D121206) and the Natural Science Foundation of Modern College of Humanities and Sciences of Shanxi Normal University (2018JCYJC01).

\section{Conflicts of Interest}

The authors declare no conflicts of interest regarding the publication of this paper.

\section{References}

[1] Yang, A., Peng, M., Zhang, G., et al. (2018) Effects of Light-Oxygen Conditions on Microbial Community of PSB during Treating High Ammonia Wastewater. Process Biochemistry, 72, 137-142. https://doi.org/10.1016/j.procbio.2018.06.003

[2] Eroğlu, E., Eroğlu, I., Gündüz, U., et al. (2008) Effect of Clay Pretreatment on Photofermentative Hydrogen Production from Olive Mill Wastewater. Bioresource Technology, 99, 6799-6808. https://doi.org/10.1016/j.biortech.2008.01.076

[3] Hülsen, T., Batstone, D.J. and Keller, J. (2014) Phototrophic Bacteria for Nutrient Recovery from Domestic Wastewater. Water Research, 50, 18-26. https://doi.org/10.1016/j.watres.2013.10.051

[4] Aksu, Z. and Eren, A.T. (2005) Carotenoids Production by the Yeast Rhodotorula Mucilaginosa: Use of Agricultural Wastes as a Carbon Source. Process Biochemistry, 40, 2985-2991. https://doi.org/10.1016/j.procbio.2005.01.011

[5] Natália, M., Paz, E.D. and Maraschin, M. (2012) Supercritical Anti-Solvent Precipitation of Carotenoid Fraction from Pink Shrimp Residue: Effect of Operational Conditions on Encapsulation Efficiency. The Journal of Supercritical Fluids, 66, 342-349. https://doi.org/10.1016/j.supflu.2011.08.006

[6] George, Basil and Pancha (2014) Effects of Different Media Composition, Light Intensity and Photoperiod on Morphology and Physiology of Freshwater Microalgae Ankistrodesmus Falcatus-A Potential Strain for Biofuel Production. Bioresource Technology, 171, 367-374. https://doi.org/10.1016/j.biortech.2014.08.086

[7] Sakaki, H., Nakanishi, T. and Tada, A. (2001) Activation of Torularhodin Production by Rhodotorula Glutinis Using Weak White Light Irradiation. Journal of Bioscience and Bioengineering, 92, 294-297. 
https://doi.org/10.1016/S1389-1723(01)80265-6

[8] Zhou, Q., Zhang, P. and Zhang, G. (2015) Biomass and Pigments Production in PSB Wastewater Treatment: Effects of Light Sources. Bioresource Technology, 179, 505-509. https://doi.org/10.1016/j.biortech.2014.12.077

[9] Lee, C.S., Lee, S.A., Ahn, C., et al. (2015) Effects of Photoperiod on Nutrientremoval, Biomass Production, and Algal-Bacterial Population Dynamics in Labscale Photobioreactors Treating Municipal Wastewater. Water Research, 68, 680-691. https://doi.org/10.1016/j.watres.2014.10.029

[10] Wahidin, S., Idris, A. and Shaleh, S. (2013) The Influence of Light Intensity and Photoperiod on the Growth and Lipid Content of Microalgae Nannochloropsis sp. Bioresource Technology, 129, 7-11. https://doi.org/10.1016/j.biortech.2012.11.032

[11] Kuo, F., Chien, Y. and Chen, C. (2012) Effects of Light Sources on Growth and Carotenoid Content of Photosynthetic Bacteria Rhodopseudomonas palustris. Bioresource Technology, 113, 315-318. https://doi.org/10.1016/j.biortech.2012.01.087

[12] Hosseini, F., Malekzadeh, F., Amirmozafari, N., et al. (2007) Biodegradation of Anionic Surfactant by Isolated Bacteriafrom Activated Sludge. International Journal of Environmental Science and Technology, 4, 127-132.

https://doi.org/10.1007/BF03325970

[13] Madukasi, E.I., Dai, X., He, C., et al. (2010) Potentials of Phototrophic Bacteria in Treating Pharmaceutical Wastewater. International Journal of Environmental Science Technology, 7, 165-174. https://doi.org/10.1007/BF03326128

[14] Li, X., Wang, Y., Zhang, S., et al. (2011) Effects of Light/Dark Cycle, Mixing Pattern and Partial Pressure of $\mathrm{H}_{2}$ on Biohydrogen Production by Rhodobacter phaeroides ZX-5. Bioresource Technology, 102, 1142-1148. https://doi.org/10.1016/j.biortech.2010.09.015

[15] Simionato, D., Sforza, E., Corteggiani, C.E., et al. (2011) Acclimation of Nannochloropsis gaditana to Different Illumination Regimes: Effects on Lipids Accumulation. Bioresource Technology, 102, 6026-6032. https://doi.org/10.1016/j.biortech.2011.02.100

[16] Yang, A., Zhang, G., Lu, P., et al. (2017) Enhancing Protein to Extremely High Content in PSB during Biogas Slurry Treatment. Bioresource Technology, 245, 1277-1281. https://doi.org/10.1016/j.biortech.2017.08.109

[17] Bernacchi, C.J., Portis, A.R., Nakano, H., et al. (2002) Temperature Responses of Mesophyll Conductance Implications for the Determination of Rubisco Enzyme Kinetics and for Limitation to Photosynthesis in Vivo. Plant Physiology, 130, 1992-1998. https://doi.org/10.1104/pp.008250

[18] Kaewsuk, J., Thorasampan, W., Thanuttamavong, M., et al. (2010) Kinetic Development and Evaluation of Membrane Sequencing Batch Reactor (MSBR) with Mixed Cultures PSB for Dairy Wastewater Treatment. Journal of Environmental Management, 91, 1161-1168. https://doi.org/10.1016/j.jenvman.2010.01.012 